\title{
REVISED What do hypnotics cost hospitals and healthcare?
}

\section{[version 2; peer review: 2 approved]}

\author{
Daniel F. Kripke (iD) \\ University of California San Diego, La Jolla, CA, 92037-2226, USA
}

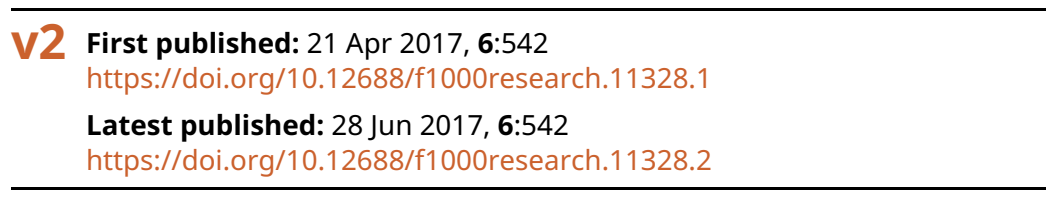

\section{Abstract}

Hypnotics (sleeping pills) are prescribed widely, but the economic costs of the harm they have caused have been largely unrecognized. Randomized clinical trials have observed that hypnotics increase the incidence of infections. Likewise, hypnotics increase the incidence of major depression and cause emergency admissions for overdoses and deaths. Epidemiologically, hypnotic use is associated with cancer, falls, automobile accidents, and markedly increased overall mortality. This article considers the costs to hospitals and healthcare payers of hypnotic-induced infections and other severe consequences of hypnotic use. These are a probable cause of excessive hospital admissions, prolonged lengths of stay at increased costs, and increased readmissions. Accurate information is scanty, for in-hospital hypnotic benefits and risks have scarcely been studied -- certainly not the economic costs of inpatient adverse effects. Healthcare costs of outpatient adverse effects likewise need evaluation. In one example, use of hypnotics among depressed patients was strongly associated with higher healthcare costs and more short-term disability. A best estimate is that U.S. costs of hypnotic harms to healthcare systems are on the order of $\$ 55$ billion, but conceivably might be as low as $\$ 10$ billion or as high as $\$ 100$ billion. More research is needed to more accurately assess unnecessary and excessive hypnotics costs to providers and insurers, as well as financial and health damages to the patients themselves.

\section{Keywords}

hospital costs, health care costs, hypnotics and sedatives, infection, depressive disorders, overdose, mortality, epidemiology

Open Peer Review
Approval Status
version 2
(revision)
28 Jun 2017
version 1
21 Apr 2017
...................................................................
1. Michael A. Grandner, University of Arizona,
Tucson, USA
2. Leon C. Lack, Flinders University of South
Australia, Adelaide, Australia
Repatriation General Hospital, Daw Park,
Australia
Any reports and responses or comments on the
article can be found at the end of the article.
view


Corresponding author: Daniel F. Kripke (DanKripke@gmail.com)

Author roles: Kripke DF: Conceptualization, Data Curation, Formal Analysis, Investigation, Methodology, Resources, Writing - Original Draft Preparation, Writing - Review \& Editing

Competing interests: The author has no financial interests or conflicts to declare. The author was the Co-Director of Research at the Scripps Clinic Viterbi Family Sleep Center until May, 2016. Since the 1979 publication of hypnotics' epidemiology from the American Cancer Society CPSI study, the author has been a frequent critic of hypnotics' risks and benefits, especially through his non-profit internet web site, www.DarkSideOfSleepingPills.com. He has advised the USA Food and Drug Administration to take certain actions to reduce hypnotic risks (Petition available at https://www.regulations.gov/docket?D=FDA-2015-P-3959), and related litigation has arisen to encourage FDA action.

Grant information: The author(s) declared that no grants were involved in supporting this work.

Copyright: @ 2017 Kripke DF. This is an open access article distributed under the terms of the Creative Commons Attribution License, which permits unrestricted use, distribution, and reproduction in any medium, provided the original work is properly cited.

How to cite this article: Kripke DF. What do hypnotics cost hospitals and healthcare? [version 2; peer review: 2 approved] F1000Research 2017, 6:542 https://doi.org/10.12688/f1000research.11328.2

First published: 21 Apr 2017, 6:542 https://doi.org/10.12688/f1000research.11328.1 


\section{REVISED Amendments from Version 1}

Version 2 responds to the advice of both reviewers by more carefully highlighting the differences between harms shown to be (at least partly) caused by hypnotics versus those harms inferred mainly from epidemiological evidence of association with hypnotics. Hypnotics are confirmed as being a partial cause of harms demonstrated by randomized controlled trials or recorded in death certificates as causes of death. Harms inferred from epidemiological association might or might not be caused in part by hypnotics, since even in studies controlling as much as possible for possible confounding by comorbidities and other factors, it is impossible to exclude all potential confounding factors of associations. In comments responding to each review of Version 1, the evidence for causality is explained at some length, but even more detail and documentation can be found in several of the references available by quick links. Several of the references also discussed the counterbalancing dangers that epidemiological association may underestimate the harms that hypnotics cause. In any case, the author and reviewers agree that much more research is needed. Hopefully new cost research will be stimulated by this presentation.

In commenting on the reviews, the author also emphasized that clinical decisions need to be made almost daily by physicians and care administrators and payers, even without waiting for more research. That is why the author attempted to present the best data that could currently be assembled, even while frequently reminding readers of the limitations.

Several additional references have been added in Version 2.

See referee reports

\section{Briefly summarizing the risks of hypnotics}

Evidence of hypnotic harms is growing - the American Geriatrics Society has recommended that the popular hypnotic drugs be avoided for older patients, who are almost half of hospital patients $^{1}$. Similarly, the American College of Physicians (ACP) recommended that cognitive behavioral therapy should be the firstchoice treatment for insomnia, and the ACP guideline expressed doubt on whether hypnotics were worth the risks, even as secondary choices for short-term use ${ }^{2,3}$. A 2017 American Academy of Sleep Medicine (AASM) guideline reiterated that cognitive-behavioral therapy is the first-choice treatment for insomnia. For pharmacologic treatment of chronic insomnia, AASM gave "WEAK" positive recommendations for use of certain hypnotics, but qualified those recommendations by conceding inadequate evidence concerning the severe risks of hypnotic drugs discussed below, by conceding that their recommendations were limited to insomnia patients without much comorbidity (probably the minority), and by noting that their recommendations might not be applicable to payer perspectives ${ }^{4,5}$.

The more severe risks of hypnotic drugs are rarely recognized.

- Randomized controlled trials show:

a) Hypnotics increase incidence of infections, with a mean $44 \%$ increase in controlled trials ${ }^{6}$. Moreover, infections are associated with depression and suicide ${ }^{7}$.

b) Hypnotics increase the incidence of major depression by more than two-fold ${ }^{8}$.
- Death certificates list hypnotics and other benzodiazepine agonists among causes of as much as 1 out of 3 U.S. opiate overdose deaths and may be present in about half of suicides ${ }^{7}$.

- Epidemiologic studies demonstrate more risks associated with hypnotics:

a) In-hospital falls, e.g. over 3 times as many falls have been observed among patients receiving zolpidem ${ }^{9}$. Outpatient falls are also increased.

b) Hypnotic use is associated with up to double the motor vehicle crash rate $^{10}$.

c) Emergency room visits related to hypnotic ingestions have been increasing ${ }^{11}$.

d) Rates of specific cancers, especially lung and esophagus, have multiplied among hypnotic users ${ }^{7}$.

e) According to electronic records systems in 5 countries, overall mortality appeared increased 2-fold to 4-fold among patients receiving hypnotics, after adjustments for comorbid risk factors and confounders ${ }^{7}$.

Hypnotic harms to patients have been documented in more detail elsewhere, with critiques on the strengths and limitations of such evidence $^{7,12}$. It is important to recognize that causality of some of these harms has been supported by randomized controlled trials or death certificates, and for other associated harms, demonstrated association may not be sufficient evidence for causality because of confounding comorbidities. Here the focus is on estimating financial harms to health systems even when lacking precise estimates of the hypnotics-caused components of these harms.

What has been missing from current documentation is a detailed report on the cost of hypnotics to hospitals, insurers, and managed care, where the minimal benefits are weighed against the severe harms. Factual economic data have been so sparse that we must use fragmentary evidence and some speculation to estimate how much hypnotics cost the U.S. medical systems. Additional studies are needed before precise cost estimates can be made.

\section{The benefits of hypnotics are trivial or absent, without documented cost savings}

An authoritative systematic review biased towards hypnotics, limited to subjective outcomes of outpatient insomnia patients, restricted to published controlled trials, and including studies of greaterthan-recommended doses, found low-strength evidence for weak benefits for two " $\mathrm{Z}$ " hypnotics used mainly in doses higher than recommended ${ }^{3,7}$. Insufficient evidence of any benefit was found for the other benzodiazepine agonists ${ }^{3}$. Moreover, the authors stated that, "it is not known how many minutes' change in SOL, TST, or WASO indicate clinically meaningful improvement ${ }^{3}$." In other words, it is not known if the weak benefits reported were clinically meaningful even at high doses that are considered unsafe. An older definitive review of objective polysomnographic data that included data from unpublished trials concluded that hypnotics produced 
little or no objective improvements in total sleep in currentlyrecommended doses and no verified overall health benefits ${ }^{7}$.

\section{Available information about the cost of hypnotic harms to hospitals and healthcare}

Up to now, medical literature has projected costs of insomnia harms but has hardly mentioned what the harms from treating with hypnotics may cost. The presence of insomnia is obviously confounded by association with prescription of hypnotics, though not as closely as one might expect ${ }^{7,12}$. In a study of 55,000,000 managed care patients, only $31 \%$ of those receiving hypnotic medication had a diagnosis of insomnia ${ }^{13}$. The fraction of insomnia patients receiving hypnotics is quite variable depending on the patient samples and definitions of insomnia. Another complication is that using hypnotics may actually cause insomnia ${ }^{14}$, at least following hypnotic withdrawal. For example, in the long run, CBT-treated patients tapered off zolpidem slept better over time than a contrast group randomly provided with continuing zolpidem ${ }^{15}$. Consequences of insomnia such as absenteeism, automobile crashes, and increased medical costs were estimated to be costing the U.S. over $\$ 15$ billion in $1993^{16}$. Several more recent cost estimates have been far higher, as high as $\$ 216$ billion in 2015 dollars ${ }^{17}$. These studies generally made little attempt to differentiate costs caused by insomnia itself from costs of confounding comorbidities and correlated hypnotic harms ${ }^{18}$. Some insomnia cost studies were sponsored by hypnotic manufacturers or others with interests in attributing the costs to insomnia.

Several studies have attributed costs associated with hypnotic prescribing to insomnia, ignoring that less than half of the prescriptions are given to patients with diagnosed insomnia ${ }^{13,19}$. Moloney et al. found that due to recent "medicalization" of sleeplessness, from 1993 to 2007, hypnotic prescribing grew much more rapidly than diagnoses of insomnia, so that in physician office visits, hypnotic prescribing grew to over 3 times the rate of sleeplessness-related complaints $^{20}$. One study used a prescription claim for a hypnotic as an explicit marker for insomnia, in order to compare cohorts with and without insomnia among 87,461 depressed patients. Hypnotic use was associated with more comorbidity-adjusted hospitalization, more frequent ER visits, 12-month healthcare costs that were $\$ 3,918$ higher, and more short-term disability ${ }^{21}$. For the authors to attribute these cost correlates of hypnotic prescription claims to insomnia (or underlying depression) and not to the hypnotics themselves seemed illogical. A similarly flawed study of a national sample of insured workers found yearly health costs were $\$ 936$ higher among those with insomnia, but $2 / 3$ of the insomnia cohort were defined by receiving hypnotics without having received a recorded diagnosis of insomnia ${ }^{22}$. Another nationwide study found that insomnia was correlated with prolonged hospital stay, but lacked data to determine whether length of stay was more closely correlated with hypnotic use rather than with insomnia diagnoses ${ }^{23}$. A study of insomnia patients both before and after treatment versus controls found an $85 \%$ increase in health costs of insomnia patients treated with sedatives/hypnotics as opposed to insomnia patients that were not treated with hypnotics ${ }^{24}$. The authors attributed this difference to more serious underlying conditions amongst those treated, without considering the possibility that the treatment itself was increasing costs. A study in Taiwan found that in contrast with a cohort without insomnia that did not use sedatives or hypnotics, a comorbidity-matched cohort with a diagnosis of insomnia suffered more acute myocardial infarction and stroke, but only among those taking hypnotics or other sedatives ${ }^{25}$. This may suggest that after control for insomnia, it was the sedative/hypnotics causing myocardial infarctions and stroke. Other studies relating insomnia to health care costs have explicitly found greater healthcare costs among those given prescription treatment for insomnia ${ }^{26,27}$.

A Mayo Clinic study found that hospital patients who received zolpidem had a $2 \%$ longer length-of-stay (not statistically significant), possibly due to their triple hazard of falls ${ }^{9}$. Although a $2 \%$ average increase in length of stay might appear small, such small mean increases would cost billions of dollars if pervasive throughout the United States. Another study found that in-hospital benzodiazepine prescriptions were associated with $23 \%$ higher readmissions ${ }^{28}$. We must recognize that without randomized placebo controls, none of these studies can offer definite proof on whether hypnotics or insomnia cause increased health costs.

It is ironic that several of the studies that document hypnotic prescriptions as being associated with increased healthcare costs were sponsored by hypnotic manufacturers, when they had intended to attribute these costs to insomnia.

\section{In-hospital hypnotic cost benefits and risks}

Fifty years ago, it was routine to prescribe an "as-needed" hypnotic with almost every hospital admission. In 1982, Perry and Wu reviewed 331 charts of a distinguished teaching hospital and reported that, "Most surgical patients $(96 \%)$ and a large number of medical patients $(46 \%)$ had hypnotic agents prescribed on admission without a recorded reason, without the patient's request or knowledge, and without a statement in the medical chart indicating whether the therapeutic objectives were met $^{29}$." Personal communications indicate that routine hypnotic prescribing without evidence of benefit is still a common practice in many of the most renowned academic medical centers. The recent Mayo Clinic report is an example that listed only $32 \%$ of patients given zolpidem as having an insomnia diagnosis 9 .

An up-to-date systematic review of 15 in-hospital controlled trials of hypnotic drugs going back to 1983 found that only one of the included trials (of intravenous dexmedetomidine) showed a convincing advantage for sleep efficiency ${ }^{30}$, even though several of the studies involved such intravenous drugs. Out of the 15 studies, 5 showed some evidence that oral benzodiazepines reduced sleep latency, but most of the treated patients still had abnormal sleep latencies exceeding 30 minutes. The review concluded with "insufficient evidence to suggest that pharmacotherapy improves the quality or quantity of sleep in hospitalized patients suffering from poor sleep ${ }^{30}$," and no other health or cost benefits were documented.

The controlled hospital trials were not designed to assess the costs of hypnotic harms. Indeed, I know of no formal studies on the health cost of harms produced by in-hospital administration of hypnotics, whether randomized or not. It is hard to imagine how drugs that are known to increase the incidence of infection and depression and are strongly associated with in-hospital falls could fail to increase hospital costs. 


\section{Hypnotic risks cannot be justified when given to patients without diagnosed insomnia}

As previously mentioned, most prescriptions for hypnotics are given to patients without diagnosed insomnia, even though insomnia is the sole approved indication for most hypnotics. Zolpidem takes up over $70 \%$ of the contemporary U.S. hypnotics' market. Most zolpidem prescriptions have been given to patients who had one or more hazardous contraindications, such as concomitant use of opiates or other sedatives, age over 60, alcoholism, history of depression or use of antidepressants ${ }^{19,31,32}$. Most outpatient hypnotic prescriptions have been renewals beyond recommended durations at above-recommended doses ${ }^{19,32,33}$. This lack of indication or documented benefit is characteristic of hypnotic prescribing, and it is hard to understand what could justify the risks and costs of supplying the benzodiazepine-agonist hypnotics.

\section{Cost estimates for specific hypnotic harms}

Excessive mortality may be the most expensive harm caused by hypnotics. It is possible to loosely estimate the related costs. The 2006-2008 estimate from the Geisinger Health Study supplement indicated that hypnotics cause roughly $18 \%$ of all adult deaths ${ }^{34}$. Considering that about $27 \%$ of Medicare costs (U.S. government payments for healthcare of people aged mainly over 65) are incurred in the last year of life, mainly shortly before death, the costs of hypnotics to Medicare in 2015 caused by increased mortality rates could be roughly $\$ 31$ billion: $0.18 \times 0.27 \times \$ 646.2$ billion $^{35}$. Current U.S. hypnotic prescriptions may be about as frequent as they were in 2006-2008, but current Medicare expenditures in 2017 would be a bit higher. Not all Medicare expenditures in the year before death would be related to the damage cause by hypnotics, but there would be counterbalancing hypnotic-related expenditures for patients before the year of death. Moreover, a substantial portion of the medical costs would have fallen on payers other than Medicare such as Medicaid, a government health provider for all-age indigent people costing $\$ 545.1$ billion $^{35}$. A somewhat different estimate of total population last-year-of-life care for 2011 was $\$ 205$ billion $^{36}$, of which $18 \%$ would be $\$ 36.9$ billion. The number of deaths statistically associated with hypnotic use may greatly overestimate the deaths attributable causally to hypnotics, but likewise the attributable deaths may be underestimated $^{12}$. A $\$ 31$ billion yearly Medicare cost estimate is quite possibly inaccurate, but it represents, in my opinion, a reasonable estimate of the cost magnitude for hypnotic-caused mortality, based on current evidence.

The costs of hypnotic-induced infections cannot be accurately estimated. We can gain a perspective on hospital infection costs from 2013 data on the U.S. hospital costs for treatment of septicemia and pneumonia alone, which together were estimated as reaching about $\$ 33$ billion $^{37}$. Between 5-10\% of these costs came from readmissions. Hypnotics have been shown to cause infections ${ }^{6}$, e.g., benzodiazepines were associated with $54 \%$ higher rates of pneumonia ${ }^{38}$. Of course, not all infections treated in hospitals are caused by hypnotics or arose in-hospital. I might imagine that hypnotic-caused inpatient-treated infections could cost anywhere up to $\$ 20$ billion per year. Also, hospital-acquired infections might not be reimbursable by Medicare payments but might fall on other funding sources.
Hypnotics increase the incidence of depression ${ }^{7}$. Estimating that there are about 14.8 million people in the U.S. each year suffering from major depressive disorders, and that $5.8 \%$ took hypnotics ${ }^{21,39}$, the total medical costs would add up to about $\$ 3.4$ billion per year for depression attributable to hypnotics, if the added healthcare cost was around $\$ 3918$ for each person ${ }^{21,39}$.

The medical costs of falls among U.S. adults aged 65 or older were estimated to be about $\$ 32$ billion for $2015^{40}$. Of these costs, around $63 \%$ covered hospitalizations, $21 \%$ emergency department visits, and $16 \%$ outpatient visits. The average cost per fall was about $\$ 30,000$. Unfortunately, there are no data available that estimate total numbers of outpatient or inpatient falls attributable to hypnotics in the U.S. However in 2010, among patients hospitalized at the Mayo Clinic, I infer from the number of falls among patients who received zolpidem, their adjusted hazard ratio, and the total falls, that $29 \%$ of total inpatient falls could be attributable to zolpidem, although there were only data on $11.8 \%$ of patients receiving any zolpidem ${ }^{9}$. Presumably, the costs of in-hospital falls were not reimbursed by Medicare charges.

Automobile crashes in 2010 were estimated to generate $\$ 23$ billion in U.S. medical costs ${ }^{41}$. It is known that people who take sedatives such as zolpidem have higher crash rates. Taken from Washington State health plan data ${ }^{10}$, sedative users had around twice the crash rate when compared to non-users, after controlling for comorbidities. Nationally, between $3-10 \%$ of adults take a hypnotic each year, so we might infer that $3-10 \%$ of crashes could be caused by hypnotics, costing roughly $\$ 0.6-2.0$ billion per year for medical costs. I am inclined to think that the percentage of U.S. adults taking hypnotics in a given year is at the higher end of that estimate, since some studies give even higher estimates ${ }^{42,43}$, and press reports suggest current prescriptions are in a range of 40-50 million per year.

National U.S. costs of cancer medical care are projected to reach $\$ 158$ billion in $2020^{44}$. If we use the Geisinger Health Study ${ }^{34}$ as a model, $\$ 1$ to $\$ 3$ billion of cancer care costs could be associated with hypnotic use each year.

Combining costs of excess mortality, infections, depression, falls, automobile crashes, and cancer, my best estimate is that hypnotics cost hospitals and medical payers somewhere around $\$ 55$ billion per year, acknowledging an uncertainty range that likely falls between $\$ 10$ billion and $\$ 100$ billion. Similarly, assuming that from about 250 million adults in the U.S., $3 \%$ to $10 \%$ take hypnotics in a given year, and estimating yearly costs related to the hypnotics to range between $\$ 936^{22}$ and $\$ 3918^{21,22}$, we can estimate the costs to fall in between $\$ 6.3$ to $\$ 95.4$ billion (probably close to the higher figures), consistent with the cumulative cost estimate taken from harm components. Wherever the true costs may fall, within that $\$ 10$ to $\$ 100$ billion likely range, these costs are great enough that studies are needed to assess the costs more reliably.

\section{What more can be learned?}

With the recent expansion of electronic medical records, many hospital systems and insurance systems already have sufficient data in their existing electronic records to estimate the outcomes 
and costs associated with hypnotics prescribing, including hospital admissions, infections, falls, and incident delirium and dementia, lengths of stay, and readmissions. Such available data could give us a much clearer idea of costs associated with in-hospital hypnotic prescribing, but control for comorbidities and other confounders could not assure an accurate estimate of the causal component of associated costs.

Fortunately, it is becoming increasingly possible to utilize genetic data and "Mendelian randomization" to effectively compare groups who received hypnotics due to random genetic propensities with those who did not ${ }^{45}$. With the increasingly widespread development of personalized medicine, involving genotyping and whole-genome analyses, an increasing number of hospital systems will have accumulated sufficient genetic data to isolate the causal contribution of hypnotics to infection, hospitalization, depression, hospital readmissions, cancer and mortality.

Because of ethical and practical difficulties and manufacturer liability concerns, it appears unlikely that anyone will ever do large enough randomizing hypnotic vs placebo drug trials to demonstrate the costs of hypnotic harms accurately. Fortunately, an alternative randomizing strategy relying on patient choice after education and patient-empowerment has been suggested: such studies might be integrated into the wellness-promotion and costreduction programs of managed care organizations ${ }^{46}$.

\section{Conclusion}

It might be years before more reliable data are assembled on the harm costs and cost-benefits of hypnotics. Meanwhile, hospital leaders and managed care and insurance administrators would be wise to infer from available evidence that the costs of hypnotic harms exceed any cost benefits of hypnotics. A decision to protect patients from hypnotics would also protect payer budgets.

\section{Competing interests}

The author has no financial interests or conflicts to declare. The author was the Co-Director of Research at the Scripps Clinic Viterbi Family Sleep Center until May, 2016. Since the 1979 publication of hypnotics' epidemiology from the American Cancer Society CPSI study, the author has been a frequent critic of hypnotics' risks and benefits, especially through his non-profit internet web site, www. DarkSideOfSleepingPills.com. He has advised the USA Food and Drug Administration to take certain actions to reduce hypnotic risks (Petition available at https://www.regulations.gov/docket?D=FDA2015-P-3959), and related litigation has arisen to encourage FDA action.

\section{Grant information}

The author(s) declared that no grants were involved in supporting this work.
1. By the American Geriatrics Society 2015 Beers Criteria Update Expert Panel: American Geriatrics Society 2015 Updated Beers Criteria for Potentially Inappropriate Medication Use in Older Adults. J Am Geriatr Soc. 2015; 63(11): 2227-46.

PubMed Abstract | Publisher Full Text

2. Qaseem A, Kansagara D, Forciea MA, et al.: Management of Chronic Insomnia Disorder in Adults: A Clinical Practice Guideline From the American College of Physicians. Ann Intern Med. 2016; 165(2): 125-33. PubMed Abstract | Publisher Full Text

3. Wilt TJ, MacDonald R, Brasure M, et al.: Pharmacologic Treatment of Insomnia Disorder: An Evidence Report for a Clinical Practice Guideline by the American College of Physicians. Ann Intern Med. 2016; 165(2): 103-12. PubMed Abstract | Publisher Full Text

4. Sateia MJ, Buysse DJ, Krystal AD, et al.: Clinical Practice Guideline for the Pharmacologic Treatment of Chronic Insomnia in Adults: An American Academy of Sleep Medicine Clinical Practice Guideline. J Clin Sleep Med. 2017; 13(2): 307-49.

PubMed Abstract | Publisher Full Text | Free Full Text

5. Sateia MJ, Sherrill WC Jr, Winter-Rosenberg C, et al:: Payer Perspective of the American Academy of Sleep Medicine Clinical Practice Guideline for the Pharmacologic Treatment of Chronic Insomnia. J Clin Sleep Med. 2017; 13(2): $155-7$.

PubMed Abstract | Publisher Full Text | Free Full Text

6. Joya FL, Kripke DF, Loving RT, et al:: Meta-analyses of hypnotics and infections: eszopiclone, ramelteon, zaleplon, and zolpidem. J Clin Sleep Med. 2009; 5(4): 377-83.

PubMed Abstract | Free Full Text

7. Kripke DF: Hypnotic drug risks of mortality, infection, depression, and cancer: but lack of benefit [version 2; referees: 2 approved]. F1000Res. 2017; 5: 918. Publisher Full Text
8. Kripke DF: Greater incidence of depression with hypnotic use than with placebo. BMC Psychiatry. 2007; 7: 42. PubMed Abstract | Publisher Full Text | Free Full Text

9. Kolla BP, Lovely JK, Mansukhani MP, et al.: Zolpidem is independently associated with increased risk of inpatient falls. J Hosp Med. 2013; 8(1): 1-6. PubMed Abstract | Publisher Full Text

10. Hansen RN, Boudreau DM, Ebel BE, et al: Sedative Hypnotic Medication Use and the Risk of Motor Vehicle Crash. Am J Public Health. 2015; 105(8): e64-e69. PubMed Abstract | Publisher Full Text

11. Bush DM: Emergency Department Visits for Adverse Reactions Involving the Insomnia Medication Zolpidem. The CBHSQ Report. Rockville (MD): Substance Abuse and Mental Health Services Administration (US); 2013-. 2013. PubMed Abstract | Free Full Text

12. Kripke DF: Mortality Risk of Hypnotics: Strengths and Limits of Evidence. Drug Saf. 2016; 39(2): 93-107.

PubMed Abstract | Publisher Full Text

13. Jhaveri M, Seal B, Pollack M, et al.: Will insomnia treatments produce overall cost savings to commercial managed-care plans? A predictive analysis in the United States. Curr Med Res Opin. 2007; 23(6): 1431-43.

PubMed Abstract | Publisher Full Text

14. Kripke DF: Hypnotics cause insomnia: evidence from clinical trials. Sleep Med. 2014; 15(9): 1168-9. PubMed Abstract | Publisher Full Text

15. Beaulieu-Bonneau S, Ivers H, Guay B, et al.: Long-Term Maintenance of Therapeutic Gains Associated With Cognitive-Behavioral Therapy for Insomnia Delivered Alone or Combined With Zolpidem. Sleep. 2017; 40(3): zsx002. PubMed Abstract | Publisher Full Text

16. Roth T: An overview of the report of the national commission on sleep disorders research. Eur Psychiatry. 1995; 10(Suppl 3): 109s-13s. PubMed Abstract | Publisher Full Text 
17. Wickwire EM, Shaya FT, Scharf SM: Health economics of insomnia treatments: The return on investment for a good night's sleep. Sleep Med Rev. 2016; 30 : 72-82.

PubMed Abstract | Publisher Full Text

18. Léger D, Bayon V: Societal costs of insomnia. Sleep Med Rev. 2010; 14(6): 379-89.

PubMed Abstract | Publisher Full Text

19. Ford ES, Wheaton AG, Cunningham TJ, et al:: Trends in outpatient visits for insomnia, sleep apnea, and prescriptions for sleep medications among US adults: Findings from the National Ambulatory Medical Care Survey 1999-2010. Sleep. 2014; 37(8): 1283-93.

PubMed Abstract | Publisher Full Text | Free Full Text

20. Moloney ME, Konrad TR, Zimmer CR: The medicalization of sleeplessness: a public health concern. Am J Public Health. 2011; 101(8): 1429-33. PubMed Abstract | Publisher Full Text | Free Full Text

21. Tian $\mathrm{H}$, Abouzaid $\mathrm{S}$, Gabriel $\mathrm{S}$, et al: Resource utilization and costs associated with insomnia treatment in patients with major depressive disorder. Prim Care Companion CNS Disord. 2012; 14(5): pii: PCC.12m01374.

PubMed Abstract | Publisher Full Text | Free Full Text

22. Pollack M, Seal B, Joish VN, et al:: Insomnia-related comorbidities and economic costs among a commercially insured population in the United States. Curr Med Res Opin. 2009; 25(8): 1901-11.

PubMed Abstract | Publisher Full Text

23. Gamaldo AA, Beydoun MA, Beydoun HA, et al:: Sleep Disturbances among Older Adults in the United States, 2002-2012: Nationwide Inpatient Rates, Predictors, and Outcomes. Front Aging Neurosci. 2016; 8: 266. PubMed Abstract | Publisher Full Text | Free Full Text

24. Anderson LH, Whitebird RR, Schultz J, et al.: Healthcare utilization and costs in persons with insomnia in a managed care population. Am J Manag Care. 2014; 20(5): e157-e165. PubMed Abstract

25. Hsu CY, Chen YT, Chen MH, et al.: The Association Between Insomnia and Increased Future Cardiovascular Events: A Nationwide Population-Based Study. Psychosom Med. 2015; 77(7): 743-51. PubMed Abstract | Publisher Full Text

26. Sarsour K, Kalsekar A, Swindle R, et al:: The association between insomnia severity and healthcare and productivity costs in a health plan sample. Sleep. 2011; 34(4): 443-50.

PubMed Abstract | Publisher Full Text | Free Full Text

27. Byles JE, Mishra GD, Harris MA, et al:: The problems of sleep for older women: changes in health outcomes. Age Ageing. 2003; 32(2): 154-63. PubMed Abstract | Publisher Full Text

28. Pavon JM, Zhao $\mathrm{Y}, \mathrm{McC}$ Connell $\mathrm{E}$, et al.: Identifying risk of readmission in hospitalized elderly adults through inpatient medication exposure. J Am Geriatr Soc. 2014; 62(6): 1116-21.

PubMed Abstract | Publisher Full Text | Free Full Text

29. Perry SW, Wu A: Rationale for the use of hypnotic agents in a general hospital. Ann Intern Med. 1984; 100(3): 441-6. PubMed Abstract | Publisher Full Text

30. Kanji S, Mera A, Hutton B, et al:: Pharmacological interventions to improve sleep in hospitalised adults: a systematic review. BMJ Open. 2016; 6(7): e012108.

PubMed Abstract | Publisher Full Text | Free Full Text

31. Moore TJ: ISMP Quarter Watch: Monitoring FDA MedWatch Reports.

Philadelphia PA, ISMP Quarter Watch; Accessed 5-6-2015.

Reference Source
32. Bertisch SM, Herzig SJ, Winkelman JW, et al:: National use of prescription medications for insomnia: NHANES 1999-2010. Sleep. 2014; 37(2): 343-9. PubMed Abstract | Publisher Full Text | Free Full Text

33. Kaufmann CN, Spira AP, Depp CA, et al.: Continuing Versus New Prescriptions for Sedative-Hypnotic Medications: United States, 2005-2012. Am J Public Health. 2016; 106(11): 2019-25.

PubMed Abstract | Publisher Full Text | Free Full Text

34. Kripke DF, Langer RD, Kline LE: Hypnotics' association with mortality or cancer: a matched cohort study. BMJ Open. 2012; 2(1): e000850.

PubMed Abstract | Publisher Full Text | Free Full Text

35. Martin AB, Hartman M, Washington B, et al:: National Health Spending: Faster Growth In 2015 As Coverage Expands And Utilization Increases. Health Aff (Millwood). 2017; 36(1): 166-76.

PubMed Abstract | Publisher Full Text

36. Aldridge MD, Kelley AS: The Myth Regarding the High Cost of End-of-Life Care. Am J Public Health. 2015; 105(12): 2411-5.

PubMed Abstract | Publisher Full Text | Free Full Text

37. Torio CM, Moore BJ: National Inpatient Hospital Costs: The Most Expensive Conditions by Payer, 2013: Statistical Brief \#204. Rockville MD, AHRQ Healthcare Cost and Utilization Project (HCUP). Accessed 2006. PubMed Abstract | Free Full text

38. Obiora E, Hubbard R, Sanders RD, et al.: The impact of benzodiazepines on occurrence of pneumonia and mortality from pneumonia: a nested casecontrol and survival analysis in a population-based cohort. Thorax. 2013; 68(2): 163-70.

PubMed Abstract | Publisher Full Text

39. Brower KJ, McCammon RJ, Wojnar M, et al.: Prescription sleeping pills, insomnia, and suicidality in the National Comorbidity Survey Replication. $J$ Clin Psychiatry. 2011; 72(4): 515-21. PubMed Abstract | Publisher Full Text

40. Burns ER, Stevens JA, Lee R: The direct costs of fatal and non-fatal falls among older adults - United States. J Safety Res. 2016; 58: 99-103.

PubMed Abstract | Publisher Full Text

41. Blincoe LJ, Miller TR, Zoloshnja E, et al.: The economic and societal impact of motor vehicle crashes, 2010 (Revised). Washington, D.C.: National Highway Traffic Safety Administration; 2015.

Reference Source

42. Chong $\mathrm{Y}$, Fryar $\mathrm{CD}, \mathrm{Gu} \mathrm{Q}$ : Prescription sleep aid use among adults: United States, 2005-2010. NCHS Data Brief. Hyattsville MD, National Center for Health Statistics. Accessed 2013; (127): 1-8. PubMed Abstract | Free Full Text

43. Johnsen M: Survey: Half of sufferers turn to sleep aids. Drug Store News. New York, New York, Lebner-Friedman, Inc. 2015; 37: 24-28. Reference Source

44. Mariotto AB, Yabroff KR, Shao Y, et al.: Projections of the cost of cancer care in the United States: 2010-2020. J Nat/ Cancer Inst. 2011; 103(2): 117-128. PubMed Abstract | Publisher Full Text | Free Full Text

45. Burgess S, Malarstig A: Using Mendelian randomization to assess and develop clinical interventions: limitations and benefits. J Comp Eff Res. 2013; 2(3): 209-12.

PubMed Abstract | Publisher Full Text

46. Tannenbaum C, Martin P, Tamblyn R, et al.: Reduction of inappropriate benzodiazepine prescriptions among older adults through direct patient education: the EMPOWER cluster randomized trial. JAMA Intern Med. 2014 174(6): 890-8.

PubMed Abstract | Publisher Full Text 


\section{Open Peer Review}

\section{Current Peer Review Status:}

\section{Version 2}

Reviewer Report 14 July 2017

https://doi.org/10.5256/f1000research.12977.r23862

(C) 2017 Grandner M. This is an open access peer review report distributed under the terms of the Creative Commons Attribution License, which permits unrestricted use, distribution, and reproduction in any medium, provided the original work is properly cited.

\section{Michael A. Grandner}

Sleep and Health Research Program, Department of Psychiatry, College of Medicine, University of Arizona, Tucson, AZ, USA

I have reviewed the revised version and believe that all issues and concerns have been adequately addressed.

Competing Interests: No competing interests were disclosed.

I confirm that I have read this submission and believe that I have an appropriate level of expertise to confirm that it is of an acceptable scientific standard.

Reviewer Report 10 July 2017

\section{https://doi.org/10.5256/f1000research.12977.r23863}

(C) 2017 Lack L. This is an open access peer review report distributed under the terms of the Creative Commons Attribution License, which permits unrestricted use, distribution, and reproduction in any medium, provided the original work is properly cited.

\section{Leon C. Lack}

1 School of Psychology, Flinders University of South Australia, Adelaide, Australia

2 Adelaide Institute for Sleep Health, Repatriation General Hospital, Daw Park, Australia

I have studied Version 2 of this article and read the authors comments and am satisfied that it should now be approved for publication.

Competing Interests: No competing interests were disclosed.

Reviewer Expertise: Circadian and sleep research; clinical research into treatment of insomnia; 
bright light therapy; napping research

\section{I confirm that I have read this submission and believe that I have an appropriate level of expertise to confirm that it is of an acceptable scientific standard.}

\section{Version 1}

Reviewer Report 19 June 2017

https://doi.org/10.5256/f1000research.12228.r23573

(c) 2017 Lack L. This is an open access peer review report distributed under the terms of the Creative Commons Attribution License, which permits unrestricted use, distribution, and reproduction in any medium, provided the original work is properly cited.

\section{Leon C. Lack}

1 School of Psychology, Flinders University of South Australia, Adelaide, Australia

2 Adelaide Institute for Sleep Health, Repatriation General Hospital, Daw Park, Australia

The author has done considerable work in assembling data relating the use of sedatives and hypnotic drugs to harmful outcomes and increased healthcare costs. The main thrust of this article is, assuming that hypnotic use causes harmful health outcomes, what would be the economic costs of this harm?

However, the question about hypnotic use by itself causing harm and health morbidity is still frustratingly not completely resolved. The author amasses a wealth of evidence associating the two, lending strength to the notion of causality but not confirming it. There is good experimental evidence showing negative effects of hypnotics including slowed reactions, cognitive and memory impairments, impaired balance arising from their sedating effects both before sleep and, for longer acting hypnotics, after sleep. However, the evidence for the direct effects of hypnotics on physical health measures is not as strong since these are largely correlation studies.

The greater increase in health morbidity and mortality in those prescribed hypnotics may arise from the possibility that hypnotics are more likely to be prescribed by health professionals in cases with greater and more serious co-morbidity and those likely to have increased mortality risk. This self selection of hypnotic prescriptions to those likely to have higher morbidity and mortality may account for all or some of the subsequent elevated risks.

The author, himself, admits that this may not be resolved without randomized control trials (with some diagnosed insomniacs not receiving hypnotics or receiving non-drug therapies instead). However, it may be difficult to obtain ethics approval for a study allocating insomnia sufferers to a non-treatment control over a long period of time (e.g 2-3 years to measure long term health outcomes). The only opportunity might be to compare pharmacotherapy alone with cognitive/behavior therapy with long term follow-ups of sleep and many health outcomes. This should be acceptable ethically. 
The difficulty with drawing causal conclusions from epidemiological studies is nicely illustrated by one of the cited references with some of the most compelling evidence, the study by Anderson, et $a l^{1}$. In their study they reported on an insomnia subset of 5,773 of which $75 \%$ were treated with a prescription medication and the other $25 \%$ were not and all were followed up after a 12 month period. The treated subset was more likely to have a mental health diagnosis and anti-depressant medications. These differences were significant between the groups at baseline which supports the notion that it is the higher morbidity patients more likely to receive hypnotic medication. These initial morbidity differences were then amplified at the follow-up and the medicated group showed greater increases in health costs (\$4276 vs \$2309) over that time. This is strong circumstantial evidence that the hypnotic medications were causing an increase in medical costs. At least one could say with greater certainty that the medications were not curing their insomnia and reducing health costs. The only lingering doubt, however, is not knowing the outcome had they not been medicated. Would they have been even worse off, no different, or, as Dr. Kripke is suggesting, better off? We simply cannot be certain until randomized controlled trials are conducted.

A crude but good analogy to the point I am making is the effect of hospitalization. Should a 70 year old with a severe chest infection be hospitalized? Those admitted to hospital certainly have a higher morbidity and mortality risk. Does that mean someone with these symptoms will be better advised to stay out of the hospital?

In the mean time, the weight of the evidence presented by the author is compelling. My only suggestion is for the author not to slip into the use of terminology that the causal connection is proven. By doing so he is in jeopardy of reducing the strength and consistency of the correlation data. Let the data be presented and just percolate in the reader's mind. It will thus be more effectively taken up than if the author takes the one step too far to insist upon the causal link. Already there is too much research being presented implying causal links between sleep variables (e.g. reported total sleep time) and health outcomes from epidemiological studies. Let's not contribute to this inappropriate trend.

\title{
References
}

1. Anderson LH, Whitebird RR, Schultz J, McEvoy CE, et al.: Healthcare utilization and costs in persons with insomnia in a managed care population.Am J Manag Care. 2014; 20 (5): e157-65 PubMed Abstract

\author{
Is the topic of the opinion article discussed accurately in the context of the current \\ literature? \\ Yes
}

Are all factual statements correct and adequately supported by citations?

Yes

Are arguments sufficiently supported by evidence from the published literature? Partly

Are the conclusions drawn balanced and justified on the basis of the presented arguments? Yes 
Competing Interests: No competing interests were disclosed.

Reviewer Expertise: Circadian and sleep research; clinical research into treatment of insomnia; bright light therapy; napping research

\section{I confirm that I have read this submission and believe that I have an appropriate level of expertise to confirm that it is of an acceptable scientific standard, however I have significant reservations, as outlined above.}

Author Response 21 Jun 2017

Daniel F. Kripke, University of California San Diego, La Jolla, USA

Dr. Lack's very thoughtful emphasis on the problem of causality highlights a crucial issue for readers of this manuscript about hypnotic costs. His review contributes to the discussion already in the manuscript calling for more studies including studies of causality. Likewise, the manuscript specifically acknowledged the problem of associational studies potentially being confounded by comorbidities. The problem of comorbidities is emphasized a bit more in Version 2. Until more reliable data become available, the manuscript argues that managed care and insurance administrators should weigh the best available evidence of whether the costs of hypnotic harms are likely to exceed the value of hypnotic benefits.

As in most areas of medicine, timely decisions about hypnotic treatments and reimbursements must be made based on incomplete and imperfect evidence. Decisions need to be made daily and cannot be deferred for years more study. We still do not have definitive randomized controlled trials about whether cigarettes cause cancer in humans. After millions of people had died from cancers "associated with" cigarette smoking, it became time to advise against cigarette smoking based on available evidence that association probably indicates a large element of causation.

The reader may be sure that this manuscript on costs never implies causation without causal evidence, but uses the word "association" whenever there is insufficient evidence of an element of causation. Some added emphasis on this distinction is included in the Version 2 revision.

This response to both reviews is a welcome opportunity to elaborate on the issues of causation versus association that were not presented at length in a manuscript about costs, since that would repeat much detail previously published. ${ }^{1,2}$ However, just as it would be an error to slip into language implying causation when only association has been demonstrated, it would be an error not to recognize existing human trials and metaanalysis confirming evidence of causation. Moreover, in the case of hypnotics, as with cigarettes, there is much animal causal data and in vitro data supporting the evidence of association studies. The sleep disorders community has been slow to recognize and replicate the existing findings as the causal evidence of serious hypnotic risks has accumulated.

Joya et al. ${ }^{3}$ performed formal meta-analysis of 38 randomized controlled trials of 8828 participants randomized to 4 hypnotics and 4383 participants randomized to placebos, in 
whom the overall infection causation hazard ratio was 1.44 (1.25-1.64, confidence interval, $\mathrm{P}<0.00001$ ). If any manufacturer could do a meta-analysis showing that this analysis was wrong, would they not have done so? How much more evidence is needed? As a matter of fact, Sanofi subsequently did an independent analysis of their Ambien data and informed the FDA that they could confirm that Ambien (zolpidem CR) causation of infections such as influenza was "probably real." 4 The FDA expert agreed. Would skeptics nevertheless question that hypnotic causation of infections such as influenza creates medical costs and sometimes deaths?

For an invited lecture, Kripke did an informal analysis of incident depressions in randomized trials of 4 hypnotics (including data available through the FDA that manufacturers did not publish). There were 5535 participants randomized to hypnotics with $2 \%$ incidence of depression and 2318 participants randomized to placebos with $0.9 \%$ incidence, yielding a depression causation risk ratio of $2.1(\mathrm{P}<0.002) .{ }^{5}$ If any manufacturer could do a larger, more formal meta-analysis showing that hypnotics do not cause depression, would one not think they would have published? In an important study of 593 participants randomized to eszopiclone and 195 randomized to placebo, the rate of discontinuation for depression was $2.0 \%$ in the eszopiclone group and $0.0 \%$ in the placebo group, a result that appears statistically significant. In their modesty, the authors did not even mention that the study had proven that eszopiclone causes infection. ${ }^{6}$ Note that these were new, incident depressions, not exacerbations, since the study excluded patients with any DSM-IV Axis I psychiatric diagnosis at baseline. ${ }^{6}$ Would skeptics nevertheless question that depression elevates medical costs and sometimes causes suicides?

The previous detailed review also discussed at length the many death certificates that mention hypnotics as one of the causes of death and likewise discussed why these are probably underestimates. ${ }^{1}$ For 2015 , the U.S. CDC's WONDER data base listed over 10,000 deaths with causes of death that included a barbiturate, benzodiazepine, or a Z-drug (the Zdrug category included anti-epileptics), but for many reasons, the 10,000 reported deaths is believed to be an underestimate. Would skeptics nevertheless argue that death certificates listing a hypnotic as a cause of death are evidence for association, not causality?

To summarize, there are certainly adequate data confirming that hypnotics cause some of the harms discussed in this manuscript and some of costs resulting. There are also controlled trials showing that hypnotics cause impaired balance and poor on-road driving performance, though controlled trials with automobile accidents or falls as endpoints have not yet reached adequate size. Further research is needed to better define the magnitude of costs from hypnotic harms, but some causal role of hypnotics in several of the harms resulting has already been confirmed.

Dr. Lack's comments are very helpful in reiterating the need for expanded studies. The problems of ethical approval are not insurmountable. If it is ethical to administer hypnotics to patients in short-term hospitalization, would it not be ethical to perform randomized trials focusing on whether hypnotic prescribing increases or decreases hospital costs? Short-term hospital studies might also provide useful evidence regarding causality of serious infections and depression. Even for early death as an endpoint, short-term randomizing clinical trials could be ethical and have adequate power. Since the 
epidemiology suggests that the greatest risk-ratio of hypnotics may be within the first 30 administrations, mainly among frail and elderly patients, randomized placebo-controlled clinical trials might only need to last 30 days among frail and vulnerable participants (who currently receive much of the hypnotics prescribed). To be sure, large numbers of participants would be needed for adequate power in relatively brief randomization designs. Another alternative would be the randomized education-patient-empowerment technique initiated by Dr. Tannenbaum. ${ }^{7}$ Another alternative would be Mendelian randomization studies. Randomizing studies of causality are feasible if those who advocate and provide hypnotics recognize their responsibilities to assess the risks and costs.

1. Kripke DF. Hypnotic drug risks of mortality, infection, depression, and cancer: but lack of benefit [version 2]. F1000Research. 2017;5: 918( http://dx.doi.org/10.12688/f1000research.8729.2 ).

2. Kripke DF. Mortality risk of hypnotics: strengths and limits of evidence. Drug Saf. 2016;39: 93-107.

3. Joya FL, Kripke DF, Loving RT, Dawson A, Kline LE. Meta-analyses of hypnotics and infections: eszopiclone, ramelteon, zaleplon, and zolpidem. J Clin Sleep Med. 2009;5(4): 37783.

4. Farkas R. Center for Drug Evaluation and Research Approval Package for: Application Number: 0199080rig1s032s0340217740rig1s013s015. Silver Spring, MD, FDA. Accessed 2013: accessible through https://www.accessdata.fda.gov/scripts/cder/daf/ under zolpidem. 5. Kripke DF. Greater incidence of depression with hypnotics than with placebo. BMC Psychiatry. 2007;7:42.

6. Krystal AD, Walsh JK, Laska E, Caron J, Amato DA, Wessel TC, Roth T. Sustained efficacy of eszopiclone over 6 months of nightly treatment: results of a randomized, double-blind, placebo-controlled study in adults with chronic insomnia. Sleep. 2003;26(7): 793-9.

7. Tannenbaum C, Martin P, Tamblyn R, Benedetti A, Ahmed S. Reduction of inappropriate benzodiazepine prescriptions among older adults through direct patient education: the EMPOWER cluster randomized trial. JAMA Intern Med. 2014;174(6): 890-8.

Competing Interests: Please see the main manuscript for the author's competing interests.

Reviewer Report 25 May 2017

https://doi.org/10.5256/f1000research.12228.r22745

(C) 2017 Grandner M. This is an open access peer review report distributed under the terms of the Creative Commons Attribution License, which permits unrestricted use, distribution, and reproduction in any medium, provided the original work is properly cited.

\section{Michael A. Grandner}

Sleep and Health Research Program, Department of Psychiatry, College of Medicine, University of Arizona, Tucson, AZ, USA

Overall this is an important contribution. A few relatively minor concerns: 
1. The term "proven" is used quite a bit. It may be better to use the more qualified "shown" or "demonstrated."

2. The paper by Moloney and colleagues (2011) demonstrates quite clearly that rates of hypnotic use are high, not really tied to insomnia diagnosis, and often chronic. This may aid in making the case in this article.

3. In addition to mentioning the ACP guideline, even the recent AASM guidelines for prescription hypnotic use state that evidence for using hypnotics is overall low.

4. There is often causal language that may be more strong than the evidence warrants. For example, it is not clear that the role of hypnotics in suicides is causal. Certainly, anecdotal evidence suggests that people overdose on sleeping pills, but the cited report has a whole paragraph about suicides that makes mostly circumstantial connections. Clearly there is a relationship, but the causal role of hypnotics is not so clearly demonstrated.

5. If hypnotics don't produce benefits, then why do people keep taking them? For example, even if the medications do not directly impact on sleep, there may be evidence that the effects on suppressing memory may outweigh the effects on sleep. So they may not actually improve sleep much but reduce the memory or perception of sleeplessness. If this reduces the discomfort associated with insomnia (i.e., it removes your memory for the events) then it could potentially have some sort of reinforcing benefit in that regard. Just saying that there are no benefits may be a bit oversold.

6. The "Detailed estimates" section does not actually include detailed estimates. Rather, it provides several general estimates for a number of specific pathways by which hypnotics could induce harms. Perhaps this section could be better labeled.

Is the topic of the opinion article discussed accurately in the context of the current literature?

Yes

Are all factual statements correct and adequately supported by citations? Yes

Are arguments sufficiently supported by evidence from the published literature? Yes

Are the conclusions drawn balanced and justified on the basis of the presented arguments? Partly

Competing Interests: No competing interests were disclosed.

I confirm that I have read this submission and believe that I have an appropriate level of expertise to confirm that it is of an acceptable scientific standard, however I have significant reservations, as outlined above. 
Author Response 26 May 2017

Daniel F. Kripke, University of California San Diego, La Jolla, USA

Dr. Grandner's has provided several very helpful suggestions which will be incorporated in a revision of the manuscript after the initial reviews. He mentioned two points of interest deserving comment here.

First, there is the question of whether there is evidence that hypnotics cause suicide, going beyond the extensive evidence for association. This is discussed in more detail in my recent more detailed review of the evidence for hypnotic harms: doi:

10.12688/f1000research.8729.2. There are several kinds of evidence. Controlled trials and meta-analysis have shown that hypnotics cause incident depressions and cause incident infections. Controlled trials are our best tests of causality. There is much new evidence that infection causes depression and suicides, and depression itself is widely believed to be the main cause of suicide. Second, in a narrower sense, when a medical examiner reports a hypnotic drug as a cause of intentional overdose death (and there are thousands of such examples), that is an expert finding of causality. Since no specific costs of suicides and suicide attempts could be included in the hypnotic cost estimates offered, causality of suicide is not a key issue for the manuscript being reviewed. More study is certainly needed. Incidentally, my petition to the FDA specifically mentioned suicides as one endpoint which should be incorporated in expanded Phase IV randomized safety trials of hypnotics.

Second, there is the question of why people keep taking hypnotics. This is a question for the ages, since throughout the history of magical beliefs and shamanism, people have consumed countless remedies including sleep remedies that are scientifically considered non-beneficial. Moreover, benzodiazepine-agonist hypnotics are known to be addicting drugs that are sometimes sought for pleasure, but equally important, these hypnotics cause withdrawal insomnia. There is much evidence that people persist in using hypnotics because of the withdrawal insomnia and anxiety that occur when consumers try to stop. As the reviewer suggested, people may take hypnotics seeking the amnesia that hypnotics produce, just as alcoholics drown their sorrows. That amnesia has not been recognized and advertised as a medical benefit. I am not aware of evidence that hypnotic-induced amnesia is medically beneficial, though it does often elicit a favorable subjective report. In hospitals, there might be an argument for helping patients to forget their anxieties, pains, and discomforts, but if the same amnesic effects contribute to falls, confusion, and dementia, it may be a costly strategy.

Competing Interests: Please see my statement of competing interests in the main article. 
The benefits of publishing with F1000Research:

- Your article is published within days, with no editorial bias

- You can publish traditional articles, null/negative results, case reports, data notes and more

- The peer review process is transparent and collaborative

- Your article is indexed in PubMed after passing peer review

- Dedicated customer support at every stage

For pre-submission enquiries, contact research@f1000.com 